\title{
O MERCADO DE MANGÁS E A CULTURA DA CONVERGÊNCIA: DESCENTRALIZANDO AS DECISÕES
}

\section{THE MANGA MARKET AND THE CONVERGENCE CULTURE: DECENTRALIZATING THE DECISIONS}

Ricardo Oliveira de Freitas ${ }^{1}$

Danilo Andrade Bittencourt ${ }^{2}$

Resumo: Desde a década de 2000, o mercado de mangás no Brasil conta com um relevante fandom consumidor que discute e organiza eventos. Contudo, com o advento da internet, as opiniões e ações destes fãs passaram a interferir, de forma cada vez mais incisiva, nas decisões de mercado de grandes editoras. Narrativas que antes dependiam de grandes emissoras e editoras para adentrar o mercado nacional, hoje são acessíveis graças à livre tradução e distribuição de fãs no espaço virtual. Este artigo resulta de uma breve investigação de viés exploratório e alicerçada no levantamento de dados bibliográficos sobre esta nova dimensão na distribuição de mangás. $\mathrm{O}$ evento para fãs Anime Friends e as atividades do blog MBB Anikenkai ilustram e confirmam a existência deste novo cenário. Abre-se um novo horizonte de investigações: o da análise da distribuição dos mangás e das suas diferentes faces midiáticas, levando em conta a interação entre fãs e editoras de mangá.

Palavras-chave: Mangás. Cultura da convergência. Cibercultura. Fandom.

Abstract: Since the 2000s, the Brazilian manga market has developed a significant fandom consumer kind, which discuss and organize conventions. Nevertheless, with the advent of the internet, opinions and activities of these fans increasingly began to interfere incisively in the decisions of the major publishing houses market. Narratives that once only depended on major broadcasters and publishing houses are today accessible due to fan free translation and distribution on the web. This article seeks a brief investigation of an exploratory character layed on the compilation of bibliographic data about this new dimension of manga distribution. The Anime Friends fan convention and MBB Anikenkai blog activities help figure out and confirm the existence of this new scenario. A new horizon of researches arises through the analysis of the distribution of manga and its different media faces also regarding the interaction between fans and manga publishing houses.

Keywords: Manga. Convergence culture. Cyber culture. Fandom.

\footnotetext{
${ }^{1}$ Universidade do Estado da Bahia (UNEB), Salvador, Doutor em Comunicação e Cultura (UFRJ), Professor Titular. E-mail: ricofrei@gmail.com

${ }^{2}$ Universidade do Estado da Bahia (UNEB), Salvador, Desenhista, Bacharel em Desenho Industrial. E-mail: daniloabittencourt@gmail.com
} 


\section{INTRODUÇÃO}

Monstros colecionáveis, alienígenas, samurais, robôs gigantes e espíritos. Estes são alguns dos elementos mais presentes nas produções do mass media japonês, especialmente em suas histórias em quadrinhos, os mangás. Apesar de ser um país tão diferente em seus hábitos e formação cultural, o Japão conseguiu difundir sua cultura pop pelo mundo. A "invasão" começou na década de 1970 e, com o avançar do tempo, mais filmes, séries, animações, games e mangás adentraram os mercados culturais do Ocidente. Em uma odisseia de grande retorno financeiro, as produções nipônicas alcançaram a Europa, a América do Norte e Latina, incluindo o Brasil, lar da maior população japonesa fora do Japão, e responsável pela incursão das primeiras obras.

Ao longo dos anos, um público fiel se desenvolveu na companhia de diversas narrativas seriadas para a televisão. Foi o caso de National Kid (1960), Cavaleiros do Zodíaco (1986), Dragon Ball (1996) e Naruto (2007); os três últimos, vale ressaltar, exemplos de animês, ou seja, animações ao estilo nipônico, detentoras de estética em muito semelhante à dos mangás. Ao longo de algumas gerações seus fãs saberiam o motivo desta contiguidade, até porque, passaram a ter acesso aos mangás que, em muitos casos, deram origem às suas séries animadas favoritas. Ao contrário do que ocorre no Japão onde o público tem, quase sempre, um primeiro contato com as séries em sua versão em mangá, no ocidente o contato inicial geralmente se dá com a versão animada:

Inspirando séries de TV, os mangás espalharam sua influência pelo mundo, pois os seriados, principalmente os desenhos animados, são os grandes embaixadores culturais do país há décadas, muito mais do que os quadrinhos que os inspiraram. Nesse aspecto, os animes foram os grandes divulgadores do traço de mangá, antes de eles serem publicados fora do Japão. Antes de a narrativa em quadrinhos dos mangás vir a público, os traços característicos já eram conhecidos em vários países, graças às boas audiências das séries animadas (NAGADO, 2005, p. 52).

Seguindo esta tendência, editoras como a Conrad e a $J B C$ deram prioridade, em seus primeiros lançamentos, à títulos conhecidos do público em versões animadas, a exemplo de Samurai X (2001) e Sakura Card Captors (2001). A estratégia "em caso de sucesso na televisão, publicaremos o mangá" foi a dominante durante um longo período. Pelo menos até os 
anos 2000. Hoje, podemos notar que ocorreram mudanças sensíveis em comparação com este passado próximo. Do patrimonialismo das emissoras e editoras, baseadas principalmente nos números de vendas e audiência, a motivação para a distribuição das obras passou para uma lógica diversa, atrelada (também) às informações veiculadas na internet, mais especificamente às opiniões dos fãs.

Casos como os de Genshiken (2014) e Elfen Lied (2012), títulos que jamais foram lançados em suas versões animadas no Brasil mas que, ainda sim, tiveram suas versões quadrinísticas traduzidas e publicadas em território nacional, demonstram que a motivação para a publicação no Brasil já não está tão atrelada à televisão (pelo menos não à televisão brasileira). Os fansubers - grupos de fãs que se reúnem com o objetivo de legendar (e até mesmo dublar), de forma independente, os animes recém exibidos no Japão - e os scalators - que escaneiam e traduzem os mangás - encurtaram o caminho da distribuição das obras que, anteriormente, passava somente pelos estúdios proprietários dos direitos das obras, emissoras de televisão e editoras. O resultado foi o acesso rápido (e muitas vezes ilegal) do público às obras, diretamente das matrizes japonesas (emissoras e editoras).

Consequentemente, este fenômeno reverberou nas escolhas dos grupos tradicionais de editoras e emissoras no Ocidente. A diáspora dos animês da televisão evidencia o fim da dependência entre mangás e animações no Brasil, ao menos da maneira com a qual se configurava nas décadas anteriores:

Há cerca de 40 anos, os fãs ocidentais de animês, por exemplo, ficavam sujeitos a decisões empresariais, tanto na escolha de títulos como de horários na grade de programação da TV. A escolha resumia-se a ou assistir o que estava disponível naquele exato momento, naquele lugar específico, ou desligar o aparelho televisor. Com o surgimento do vídeo as possibilidades melhoraram um pouco: é possível gravar os programas e assisti-los na hora e local desejado. Entretanto, no ciberespaço questões temporais e espaciais ganham outras proporções, a circulação de conteúdo é enorme, se comparada com as mídias tradicionais; o público tem a possibilidade de participar de forma antes impossível na divulgação dos produtos de seu interesse (CARLOS, 2009, p. 10).

O presente artigo visa descrever este novo horizonte de investigações, que desperta o interesse dos pesquisadores pela mudança na configuração da distribuição da cultura pop japonesa no Brasil, especialmente no que se refere aos mangás, onde verifica-se uma modificação 
no modo com o qual os espectadores atuam diante do mercado cultural. Para desbravar esta nova realidade e abrir novas possibilidades de reflexão acerca do tema, aqui é conduzida uma pesquisa de viés exploratório e baseada no levantamento de dados bibliográficos disponíveis. Dentre estes, destacam as investigações de pesquisadores como Giovana Carlos (2009, 2011), Victor Corrêa e Roberto dos Santos (2014), além das considerações sobre a distribuição das obras no Brasil de Alexandre Nagado (2005) e das conceituações sobre cultura da convergência de Henry Jenkins (2008) e cibercultura por Pierre Levy (1999).

\section{O EVENTO DE FÃS E A CONVERGÊNCIA}

No dia 29 de Julho de 2014, o portal UOL, um dos mais acessados do Brasil, estampou em sua primeira página a chamada: "Fora da TV, mercado de animê no Brasil se garante na internet e em eventos". Na matéria, Pablo Miyazawa (2014) chamava atenção para o grande (e crescente) público recebido pelo evento Anime Friends em São Paulo. Voltado à cultura pop - que inclui diversos veículos do mass media, como histórias em quadrinhos, filmes, games, animações e séries - o encontro dedica-se, principalmente, às produções oriundas da indústria cultural japonesa.

Miyazawa entrevista um dos organizadores da festa, Takashi Tikasawa, e este aponta para o ascendente interesse de empresas - inicialmente de pequeno e médio porte, hoje cada vez maiores - em patrocinar o Anime Friends, dado o grande público (cerca de 110 mil pessoas) reunido no Campo de Marte, Zona Norte de São Paulo. Devemos ressaltar que, além do encontro paulista, existem empreendimentos similares em outras cidades do país, como o $A$ nime Wings, no Rio de Janeiro, e o Anipolitan, em Salvador. Todos funcionando, em certa medida, como "termômetros" do comportamento deste fandom ${ }^{3}$. Ao contrário do que ocorria desde os anos 1970, quando o consumo deste tipo de conteúdo estava intimamente relacionado com a televisão, nota-se que o fortalecimento deste público nos últimos anos ocorre à despeito da recente diáspora das produções japonesas das emissoras brasileiras. Até porque, o uso da internet passou a fazer parte do cotidiano de grande parte destes novos fãs:

\footnotetext{
3 Termo que une as palavras, em inglês, "fan" (fã) e "kingdom" (reino). Diz respeito a um grupo de pessoas, unido pelo apreço a determinada ou determinadas produções culturais.
} 
Atualmente, os eventos para fãs de cultura pop funcionam como o porto seguro de um público devoto, menos dependente do mainstream do que nunca. Além de mais jovem e eclético do que dez anos atrás, o atual frequentador também se interessa em manter viva a chama do underground, cultuando artistas obscuros só conhecidos pela internet e cobiçando não apenas merchandising oficial, mas também produtos customizados por outros fãs (MIYAZAWA, 2014).

Como vimos, até os anos 2000 a "febre" da cultura pop japonesa estava intimamente ligada à exibição de desenhos animados na televisão aberta. Até mesmo o comércio de mangás era submisso ao que era ali exibido. No entanto, as produções nipônicas foram, pouco a pouco, desaparecendo da televisão, especialmente a aberta, espaço cativo desde a década de 1980. Entre os motivos, está o "elevado custo de licenciamento de novos títulos com as produtoras japonesas" (MIYAZAWA, 2014). Em contraponto, assistimos ao avanço do acesso à internet. Os usuários desta rede assumiram o "bastão" e deram continuidade ao processo iniciado nas grandes emissoras de TV:

A internet, por outro lado, manteve aceso o culto ao animê, em uma revolução afastada da grande mídia, mais robusta e autossuficiente. Se hoje esses programas são raros nas grades de Globo, Bandeirantes e Record, eles estão mais do que nunca à disposição para download e streaming ilegais, oferecidos por fãs engajados que traduzem episódios e os disponibilizam no mesmo dia em que são exibidos no Japão (MIYAZAWA, 2014).

O que antes dependia do intermédio de grandes empresas de telecomunicação, baseando a disponibilização e continuidade dos títulos em números de audiência, hoje sobrevive da livre iniciativa de fãs que decidem gravar, traduzir e compartilhar as produções nipônicas, mesmo quebrando as leis de direitos autorais. Apesar de não cobrarem dinheiro pelo serviço, estes fãs beneficiam-se da publicidade veiculada em seus websites e de uma recompensa "simbólica” que vem, “(...) da reputação de competência que é constituída a longo prazo na ‘opinião pública' da comunidade virtual” (LÉVY, 1999: 128). Para além do amadorismo ilegal, novas empresas (estas legais) também vêm explorando a transmissão via web, a exemplo da Crunchyroll (especializado em animês) e da Netflix (conteúdo bastante variado com filmes, séries e documentários diversos) que fornecem aos seus usuários vantagens inexistentes na televisão tradicional como poder assistir a programação quando e onde quiser, além de ter acesso a conteúdo antigo. 
Não só o acesso às animações foi ampliado, como o mercado de mangás, que nos interessa especialmente, segue cada vez maior com o aumento no número de títulos em oferta e na qualidade das edições publicadas em solo nacional:

Nos últimos anos, houve um estouro na quantidade de títulos disponíveis oficialmente. "Há dez anos tínhamos uns dez mangás em bancas. Hoje são mais de 40. Temos tiragens menores, mas mais variedade e qualidade do que antes", diz Cassius Medauar, gerente de conteúdo da editora JBC, que lança cerca de 15 títulos por mês. A principal concorrente, a editora Panini, publica quantidade de edições semelhante pelo selo Planet Mangá. "O público mudou bastante", afirma Medauar. "O mercado de mangás se consolidou, temos uma base fiel e um público que entende e conhece os títulos, e com isso ficou mais exigente." (MIYAZAWA, 2014).

Para entender porque "o público mudou bastante", como constata Medauar, podemos levar em consideração algumas colocações de Henry Jenkins (2008). Estas nos fornecem ferramentas teóricas úteis para a compreensão deste fenômeno. Apontamos aqui, principalmente para seu conceito de convergência:

Por convergência, refiro-me ao fluxo de conteúdos através de múltiplos suportes midiáticos, à cooperação entre múltiplos mercados midiáticos e ao comportamento migratório dos públicos dos meios de comunicação, que vão a quase qualquer parte em busca das experiências de entretenimento que desejam. Convergência é uma palavra que consegue definir transformações tecnológicas, mercadológicas, culturais e sociais, dependendo de quem está falando e do que imaginam estar falando (JENKINS, 2008: 29).

A partir da citação acima, podemos perceber o grau de complexidade da questão que abordamos, visto que esta atravessa as linguagens da animação e dos quadrinhos - resultado da tendência, recorrente no universo da cultura pop japonesa, de adaptar determinadas histórias e personagens para diferentes mídias - também tratamos das preferências de indivíduos, de comunidades de fãs e de grandes empresas. Decerto, o cenário descrito pela matéria do UOL levanta discussões acerca da transmissão de conteúdos e dos impactos que esta mudança de comportamentos tem causado no mercado de mangás. Podemos perceber aqui um campo fértil para novas investigações que, em alguma medida, já foram iniciadas. 


\title{
2. A DESCENTRALIZAÇÃO DE DECISÕES E UM NOVO HORIZONTE DE INVESTIGAÇÕES
}

Além de Henry Jenkins, outros pesquisadores vêm desenvolvendo trabalhos acerca da cibercultura, conceito útil no entendimento deste novo fenômeno que marca o mercado e a distribuição de quadrinhos, notável pela interferência dos espectadores através da internet. Além da convergência presente na comunicação de massa contemporânea, temos também, o conceito de comunidade virtual proposto por Pierre Levy (1999). Para Levy, a comunidade virtual é “(...) construída sobre as afinidades de interesses, de conhecimentos, sobre projetos mútuos, em um processo de cooperação ou de troca, tudo isso independentemente das proximidades geográficas e das filiações institucionais" (LÉVY, 1999, p. 127).

A aderência deste conceito à questão aqui exposta fica evidente quando levamos em conta investigações mais específicas, decerto, àquelas que se interessam pela cultura pop japonesa, em especial pelo mangá no contexto da cibercultura. Destacamos aqui as pesquisas de Giovana Carlos (2009, 2011):

\begin{abstract}
O cenário atual do consumo de produtos da cultura pop japonesa passa em grande parte pela cibercultura. O público não mais está "preso" ao que os canais de televisão exibem ou ao que as editoras publicam. Na internet, a liberdade de consumo é maior, cada um escolhe o que deseja e se, quiser, mais do que escolher o que ler ou assistir, também pode fazer parte do processo de disponibilização desses conteúdos. (CARLOS, 2009, p. 8).
\end{abstract}

As investigações de Giovana Carlos analisam os impactos na circulação de conteúdos midiáticos da cultura pop japonesa (2009) e, mais especificamente dos mangás (2011), gerados por uma recente organização de fãs na internet: os scanlators. Para a pesquisadora, a atuação destas comunidades virtuais alcançam grandes desdobramentos, com a atuação cada vez mais ativa dos fãs, como já apontamos aqui, em diversas mídias e em um mercado competitivo:

A grande circulação de desenhos animados, live-actions4 e quadrinhos japoneses no Ocidente se deve em boa parte ao interesse de um público fã que se engaja para que isso aconteça. Olhando-se mais atentamente também se pode observar que o sucesso de séries nipônicas é concomitante com a dissemina-

\footnotetext{
${ }^{4}$ Termo cinematográfico que diz respeito à filmes que, ao contrário das animações, utilizam atores reais, de carne e osso.
} 
ção da internet, meio propício para larga divulgação e apropriação desses conteúdos. Enfim, é possível perceber como o desenvolvimento da tecnologia e da mídia transforma os processos culturais e comunicacionais de uma sociedade (CARLOS, 2009, p. 10).

A atividade do blog brasileiro $M B B$ Anikenkai que, desde o ano de 2010, vêm divulgando o mangá Genshiken (2014) através de críticas em textos curtos que acompanham de perto os lançamentos dos capítulos da série no Japão (acessados graças aos escaneamentos dos chamados scalators), exemplifica, mesmo que de maneira difusa, o efeitos do engajamento dos fãs no mercado editorial. Pouco mais de três anos após o blog iniciar a divulgação do mangá, a editora JBC anunciou o lançamento do título no Brasil (apesar da versão animada nunca ter sido formalmente exibida em território nacional). Imediatamente, Diogo Prado (2013), autor do blog, registrou sobre a notícia:

Quem me conhece sabe que Genshiken é meu mangá favorito de todos os tempos e o mangá do qual a ideia do Anikenkai surgiu e do qual o nome do Anikenkai se originou. Se já não bastasse isso, meu maior sonho "mangazeiro" sempre foi o mangá chegar ao Brasil para que mais gente pudesse conhecer a série! Inclusive, um dos meus objetivos com o Anikenkai era de alguma maneira, colaborar para que o mangá viesse para o Brasil. Não posso dizer que tive influência direta nisso, mas não posso também deixar de sentir como se tivesse completado um grande objetivo em minha vida! (PRADO, 2013, grifo nosso).

Se as atividades e discussões geradas no Anikenkai tiveram algum tipo de impacto no interesse da editora JBC pelo licenciamento do mangá Genshiken, é difícil precisar. A despeito disso, o discurso do blogueiro demonstra que, apesar da visão nebulosa em relação a questão, ele (e muitos dos seus leitores, vide comentários) se sente responsável de alguma forma. Vale ressaltar que tem se tornado comum aquilo que já ocorre em outros países: editoras passam a tratar certos blogueiros da mesma forma que tratam críticos "profissionais", filiados aos grandes veículos da mídia e, assim como um crítico é convidado para um seção especial de alguma nova produção fílmica, estes blogueiros recebem mangás da parte das editoras (de forma gratuita) para que possam escrever críticas em seus blogs. Este é um exemplo que sintetiza aquilo que conclui Henry Jenkins (2008): "às vezes, a convergência corporativa e a convergência alternativa se fortalecem mutuamente, criando relações mais próximas e mais gratificantes entre produtores e consumidores de mídia” (JENKINS, 2008, p. 46).

Outro caso notável é o da história em quadrinhos nacional Combo Rangers (1998) de Fábio Yabu. Lançada tanto em versão impressa quanto em formato digital, o quadrinho - in- 
fluenciado, em grande medida, pela estética dos mangás - lança mão de diferentes recursos para as diferentes mídias, como aborda o artigo de Victor Corrêa e Roberto dos Santos (2014). O que chama atenção para a série brasileira é que ela conquistou sua popularidade na internet, popularidade esta, que impulsionou duas publicações em formato tradicional (impresso) pelas duas maiores editoras de quadrinhos do Brasil: a JBC e a Panini. O que iniciou (e permanece) em ambiente underground, possui, ao mesmo tempo, uma face mainstream.

Apesar destes novos desdobramentos, convém seguir uma posição mais sóbria e entender que esta geração de fãs mais ativos não significa o fim da hegemonia das grandes editoras. Vale lembrar que Genshiken, assim como outras obras de grande repercussão, não é um mangá independente, ele ainda pertence a uma grande editora japonesa (Kodansha). A novidade neste caso é que a livre iniciativa de diversos fãs, que escanearam os quadrinhos, os traduziram, escreveram e discutiram sobre eles teve um impacto, em alguma medida, na publicação da obra no Brasil, através de uma das maiores editoras de mangás do país.

\section{CONCLUSÃO}

O que podemos concluir no presente artigo é que o fenômeno da convergência acaba influenciando nas formas de se ter acesso às histórias em quadrinhos. Os consumidores de mangás já adotam iniciativas que interferem diretamente nas escolhas das editoras. Decisões que antes levavam em conta a audiência de um animê no país ou as vendas do mangá em outros, hoje são influenciadas pelo comportamento das comunidades virtuais. Abre-se então um novo horizonte de investigações: o da análise das interações entre os mangás, suas várias versões mediáticas (live-action, animes, games) e a distribuição das mesmas, levando em conta a interação entre fãs e editoras de mangá.

Alguns pesquisadores, como os citados no presente artigo, já vêm se debruçando sobre este tipo de investigação. Decerto que, eventos como o Anime Friends, produções como Combo Rangers e blogs como o MBB Anikenkai oferecem amostras de uma nova tendência no mercado e na cultura de consumo dos mangás no Brasil e no mundo. Resta saber qual é o real peso da influência dos fãs na distribuição das obras, quais serão as estratégias das grandes empresas para a manutenção de seus lucros em um cenário de pirataria ostensiva e se as obras 
independentes terão, algum dia, o mesmo peso que as narrativas subsidiadas pelas grandes editoras.

\section{REFERÊNCIAS}

CARLOS, Giovana. $O(s)$ fã $(s)$ da cultura pop japonesa e a prática de scanlation no Brasil Mestrado em Comunicação e Linguagens - Universidade Tuiuti do Paraná - Curitiba - 2011

Da cultura de massa à cibercultura: o caso do fenômeno da cultura pop japonesa no Ocidente - XXXI Intercom - 2009

DOS SANTOS, R. E.; CORRÊA, V. W. Quadrinhos nacionais no ciberespaço: uma análise de Combo Ranger nos âmbitos digital e impresso. São Paulo: Galaxia - Revista do Programa de Pós-Graduação em Comunicação e Semiótica (Online), n. 27, p. 107-119, jun. 2014. Disponível em: 〈http://dx.doi.org/10.1590/1982-25542014116091>.

JENKINS, Henry. Cultura da convergência. São Paulo: Editora Aleph. 2008.

LÉVY, Pierre. Cibercultura. São Paulo: editora 34, 1999.

MIYAZAWA, Pablo. Fora da TV, mercado de anime no Brasil se garante na internet e em eventos. Portal Uol Entretenimento, 2014. Disponível em:

<http://entretenimento.uol.com.br/noticias/redacao/2014/07/29/fora-da-tv-mercado-de-animeno-brasil-se-garante-na-internet-e-em-eventos.htm>. Acesso em 29 de Julho de 2014.

NAGADO, Alexandre. O mangá no contexto da cultura pop japonesa e universal. In: LUYTEN, Sonia (org.). Cultura pop japonesa. São Paulo: Hedra, 2005.

PRADO, Diogo. Genshiken será publicado pela jbc! Notícia da década! Blog MBB Anikenkai, 2013. Dísponivel em: < http://www.genkidama.com.br/anikenkai/2013/04/12/genshikensera-publicado-pela-jbc-o-surto-e-livre/>

Recebido em: 18 de março de 2014.

Aceito em: 29 de abril de 2014. 